\title{
Safety and Efficacy of Exercise Training After Coronary Stenting in Patients With Stable Coronary Artery Disease
}

\author{
Yoshimitsu Soga, MD; Hiroyoshi Yokoi, MD; Kisaki Amemiya, MD; \\ Masashi Iwabuchi, MD; Masakiyo Nobuyoshi, MD
}

\begin{abstract}
Background: Exercise training (ET) after coronary stenting is considered to have a risk of stent thrombosis (ST). The present study investigated whether ET increases the incidence of ST in patients undergoing coronary stenting.

Methods and Results: The current study was a prospective observational study. We enrolled 3,672 patients who underwent successful coronary stenting. Patients decided whether to participate in exercise and were divided into an ET group $(n=1,592)$ and a control group $(n=2,080)$. The primary endpoint was the incidence of ST. Secondary endpoints were major adverse cardiovascular events (MACE: death, myocardial infarction, and stroke) and unscheduled hospital visits for angina. The incidence of ST and MACE were similar in both groups $(1.8 \%$ vs. $2.0 \%$, $\mathrm{P}=0.73,14.9 \%$ vs. $15.0 \%, \mathrm{P}=0.97$, respectively). Unscheduled hospital visits were significantly lower in the ET group (20.2\% vs. 27.2\%, $\mathrm{P}<0.0001)$. After adjusting for baselines, the ET group had no significant increase in ST (hazard ratio (HR) 0.86, adjusted $\mathrm{P}=0.56$ ) and MACE (HR 0.98, adjusted $\mathrm{P}=0.83$ ). The $E T$ was effective to prevent an unscheduled hospital visits for worsening angina (HR 0.67, adjusted $\mathrm{P}<0.0001$ ).
\end{abstract}

Conclusions: Moderate ET after successful coronary stenting does not increase the incidence of ST and MACE, and was effective in reducing unscheduled hospital visits for angina. (Circ J 2011; 75: 2379-2386)

Key Words: Coronary artery disease; Exercise training; Stent thrombosis

$\mathbf{E}$ xercise training (ET) is effective for improvement of exercise tolerability, ${ }^{1,2}$ symptoms, ${ }^{3,4}$ lipid concentrations,,${ }^{1,2}$ and psychosocial satisfaction, $, 5,6$ as well as for decreasing mortality $;^{7,8}$ and thus exercise is extremely useful for patients with coronary disease. Nevertheless, few patients with coronary disease participate in an official cardiac rehabilitation program, and these percentages cannot be considered sufficient. ${ }^{9}$

At present, patients who undergo revascularization often begin exercise voluntarily in the early postoperative period. However, this is limited to providing the patients with guidelines and techniques for correction of coronary risk factors and behavior modification, due to the short hospitalization period. Thus, it is unclear if the patients receive the benefits of ET. Furthermore, because rapid recovery of activity level is likely when ET is started for such patients in an early phase, it is important to evaluate the safety of ET to facilitate active participation in the therapy. Therefore, in the current study we investigated the safety and efficacy of ET in patients after elective coronary stenting.

\section{Methods}

\section{Study Population}

This study was performed as a prospective observational study. We investigated whether ET after coronary stenting would increase the incidence of stent thrombosis (ST). The study period was 36 months. The participants were patients who underwent successful elective coronary stenting (defined as residual stenosis of the target lesion $<30 \%$ without suboptimal result). Other inclusion criteria were age $>20$ and $\leq 80$ years old, no residual stenosis or scheduled to undergo revascularization. Patient enrollment was performed before discharge and the patients decided whether to participate in ET by themselves. Exclusion criteria included hemodialysis, uncontrollable hypertension, unstable angina, myocardial infarction (MI) within 4 weeks, symptomatic heart failure, hemorrhagic diatheses, severe valvular heart disease, dementia, inability to ET as a result of orthopedic or neurological limitations, symptomatic main vessel or side branch occlusions, acute closure, access site-related complications before enrollment, persistent

Received May 10, 2011; revised manuscript received June 9, 2011; accepted June 15, 2011; released online July 28, 2011 Time for primary review: 7 days

Department of Cardiology, Kokura Memorial Hospital, Kitakyushu (Y.S., K.A., M.I., M.N.); Department of Cardiac Rehabilitation, Kokura Memorial Hospital, Kitakyushu (H.Y.), Japan

Mailing address: Yoshimitsu Soga, MD, Department of Cardiology, Kokura Memorial Hospital, 3-2-1 Asano, Kokurakita-ku, Kitakyushu 802-0001, Japan. E-mail: sogacchy@yahoo.co.jp

ISSN-1346-9843 doi:10.1253/circj.CJ-11-0470

All rights are reserved to the Japanese Circulation Society. For permissions, please e-mail: cj@j-circ.or.jp 
3705 Assessed Eligibility

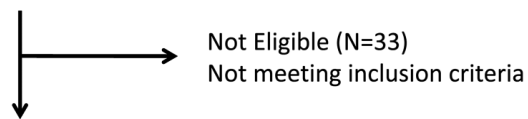

3672 Enrolled

Patients decided whether to participate exercise or not by themselves

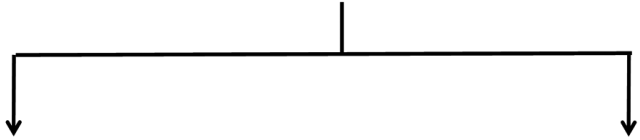

1592 Allocated to exercise group

137 died

153 Lost to follow-Up

15 withdrew consent

714 discontinued exercise

36-month follow-up

(88.5\%: 1287/1455)

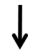

1287 completed follow-up

1592 analyzed
2080 Allocated to control group

172 died

231 Lost to follow-Up

24 withdrew consent

649 started exercise

36-month follow-up

(86.6\%: 1653/1908)

1653 completed follow-up

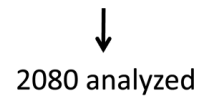

Figure 1. Participant flow through the trial. chest pain or new ST-segment deviation, or final coronary flow Thrombolysis In Myocardial Infarction grade 2 or less. ${ }^{10}$

The study was approved by the Institutional Review Board of each institution and Informed consent was obtained from the participants. This trial is registered with the University Hospital Medical Information Network-Clinical Trials Registry (UMIN-CTR), as accepted by the International Committee of Medical Journal Editors (no. UMIN000004842).

\section{Study Endpoint}

The primary endpoint of the study was cumulative incidence of ST. The secondary endpoints were the incidence of major adverse cardiovascular events (MACE, included all-cause mortality, MI, and stroke) and unscheduled hospital visit for worsening angina.

\section{Study Procedure and Exercise}

All patients were pretreated with ticlopidine ( $200 \mathrm{mg}$ daily) or clopidogrel (75 mg daily) in addition to aspirin (100-200 mg daily), and a loading dose of $300 \mathrm{mg}$ of clopidogrel was given to patients who had not previously taken this drug. Aspirin and ticlopidine were started at least 2 days before elective stenting.

Before starting ET, an exercise test on a bicycle ergometer was performed before discharge. The exercise was continued for about 20 min measured at the Borg Index 11 to 13 "relatively easy and slightly tiring". ${ }^{11}$ The same degree exercise was continued after discharge. The recommended exercise after discharge was usually walking. The ET was planned for 3 times per week or more in sessions of at least $30 \mathrm{~min}$, with exercise intensity that was between "relatively easy and slightly tiring" (between 11 and 13 on the Borg Scale) and self-monitored ET.

After discharge from hospital, lifelong oral administration of aspirin was recommended; with oral administration of a thienopyridine for at least 1 month after placement of a bare-metal stent (BMS) or lifelong after placement of a drug-eluting stent (DES). Clinical follow-up was performed at 1, 6, 12, 24, and 36 months. When a participant was judged to be at the study endpoint, the event was validated by Event Advisory Committee.

\section{Definitions}

ST was defined as follows, according to the Academic Research Consortium definition. ${ }^{12}$ Definite ST required angiographic confirmation of ST and the presence of at least 1 of the following within $48 \mathrm{~h}$ : new onset of ischemic symptoms at rest, new electrocardiographic changes suggestive of acute ischemia, or a typical rise and fall in cardiac biomarkers. Probable ST was defined as a MI in the same territory and any unexplained death within the first 30 days. Possible ST was defined as a MI in the same territory and any unexplained death after 30 days. MI was defined by a significant elevation of serum biomarkers (troponin above the MI concentration or creatinine kinase of twice the normal concentration) or new $\mathrm{Q}$ waves on the electrocardiogram. Stroke was defined as cerebral stroke that persisted for at least $24 \mathrm{~h}$ and indicated the occurrence of a neurological deficit. Patients with a left ventricular (LV) ejection fraction $<35 \%$ were regarded as having LV dysfunction. Bifurcation lesion was defined as that involving a side branch of more than $2.2 \mathrm{~mm}$ in diameter. Chronic kidney disease was regarded to be present when creatinine clearance estimated by the Cockcroft-Gould formula was $<60 \mathrm{ml} / \mathrm{min}$. Exercise habit was defined as routine exercise for at least $20 \mathrm{~min}$ at least 2 times a week and it was continued for more than 1 year. 


\begin{tabular}{|c|c|c|c|c|}
\hline & $\begin{array}{c}\text { Total } \\
(n=3,672)\end{array}$ & $\begin{array}{c}\text { Exercise (+) } \\
(n=1,592)\end{array}$ & $\begin{array}{c}\text { Exercise (-) } \\
(n=2,080)\end{array}$ & $P$ value \\
\hline Age (years) & $68.2 \pm 7.5$ & $67.4 \pm 8.5$ & $68.8 \pm 9.6$ & $<0.0001$ \\
\hline Male gender (\%) & $2,731(74.3)$ & $1,242(78.0)$ & $1,489(71.6)$ & $<0.0001$ \\
\hline BMI $\left(\mathrm{kg} / \mathrm{m}^{2}\right)$ & $24.4 \pm 2.5$ & $24.4 \pm 3.5$ & $24.3 \pm 3.1$ & 0.49 \\
\hline Hypertension (\%) & $2,255(61.4)$ & $992(62.3)$ & $1,263(60.7)$ & 0.33 \\
\hline Hyperlipidemia (\%) & $1,498(40.8)$ & $663(41.6)$ & $835(40.1)$ & 0.63 \\
\hline Diabetes mellitus (\%) & $1,647(44.9)$ & $709(44.5)$ & $938(45.1)$ & 0.73 \\
\hline Current smoker (\%) & $956(26.0)$ & $401(25.2)$ & $555(26.7)$ & 0.31 \\
\hline Exercise habit (\%) & $1,019(27.8)$ & $426(26.8)$ & $593(28.5)$ & 0.24 \\
\hline Previous PCI (\%) & $596(16.2)$ & $289(18.2)$ & $307(14.8)$ & 0.006 \\
\hline Atrial fibrillation (\%) & $183(5.0)$ & $87(5.5)$ & $96(4.6)$ & 0.25 \\
\hline Chronic kidney disease (\%) & $455(12.4)$ & $186(11.7)$ & $269(12.9)$ & 0.25 \\
\hline Cerebrovascular attack (\%) & $561(15.3)$ & $241(15.1)$ & $320(15.4)$ & 0.84 \\
\hline LV dysfunction (\%) & $320(8.7)$ & $128(8.0)$ & $192(9.2)$ & 0.20 \\
\hline Multivessel stenting (\%) & $1,008(27.5)$ & $438(27.5)$ & $570(27.4)$ & 0.94 \\
\hline Total stent length (mm) & $30.4 \pm 12.7$ & $30.3 \pm 17.2$ & $30.6 \pm 16.3$ & 0.54 \\
\hline Number of stent/patients & $1.59 \pm 0.70$ & $1.58 \pm 8.3$ & $1.60 \pm 0.82$ & 0.57 \\
\hline Mean stent diameter $(\mathrm{mm})$ & $2.95 \pm 0.37$ & $2.96 \pm 0.48$ & $2.95 \pm 0.44$ & 0.48 \\
\hline Restenosis (\%) & $652(17.8)$ & $253(15.9)$ & $399(19.2)$ & 0.01 \\
\hline Chronic total occlusion (\%) & $258(7.0)$ & $120(7.5)$ & $138(6.6)$ & 0.29 \\
\hline Bifurcation (\%) & $539(14.7)$ & $226(14.2)$ & $313(15.0)$ & 0.47 \\
\hline Use of DES (\%) & $1,679(45.7)$ & $756(47.5)$ & $923(44.4)$ & 0.06 \\
\hline \multicolumn{5}{|l|}{ Stented territory } \\
\hline $\operatorname{LAD}(\%)$ & $1,793(48.8)$ & $749(47.0)$ & $1,044(50.2)$ & 0.06 \\
\hline $\mathrm{RCA}(\%)$ & $1,610(43.8)$ & $771(48.4)$ & $839(40.3)$ & $<0.0001$ \\
\hline LCx $(\%)$ & $940(25.6)$ & $372(23.4)$ & $568(27.3)$ & 0.007 \\
\hline Bypass graft (\%) & $22(0.6)$ & $7(0.4)$ & $15(0.7)$ & 0.27 \\
\hline Left main trunk (\%) & $80(2.2)$ & $28(1.8)$ & $52(2.5)$ & 0.13 \\
\hline \multicolumn{5}{|l|}{ Medication } \\
\hline Aspirin (\%) & $3,629(98.8)$ & $1,576(99.0)$ & $2,053(98.7)$ & 0.41 \\
\hline Thienopyridines (\%) & $1,463(39.8)$ & $654(41.1)$ & $809(38.9)$ & 0.18 \\
\hline Statins (\%) & $2,160(58.8)$ & $925(58.1)$ & $1,235(59.4)$ & 0.44 \\
\hline$\beta$-blockade (\%) & $646(17.6)$ & $294(18.5)$ & $352(16.9)$ & 0.22 \\
\hline ACEI/ARB (\%) & $1,710(46.6)$ & 769 (48.3) & $941(45.2)$ & 0.07 \\
\hline
\end{tabular}

$\mathrm{BMI}$, body mass index; PCl, percutaneous coronary intervention; LV, left ventricular; DES, drug-eluting stent; LAD, left anterior descending coronary artery; RCA, right coronary artery; LCX, left circumflex coronary artery; ACEI, angiotensin converting enzyme inhibitors; ARB, angiotensin receptor blockers.

LV dysfunction was defined as ejection fraction $<35 \%$. Bifurcation lesion was defined as that involving a side branch of more than $2.2 \mathrm{~mm}$ in diameter.

\section{Statistical Analysis}

Continuous variables were reported as means \pm SD unless otherwise indicated. Continuous variables were examined by unpaired t-test or Wilcoxon rank-sum test on the basis of the distribution. Categorical variables were compared by chi-square test. Survival curves were estimated using the Kaplan-Meier method and compared by log-rank test. All analyses were based on an intention-to-treat (ITT) principle. However, with the aim of decreasing crossover effects, as-treated (AT) analysis was also performed for the group of patients who performed exercise (continuous exercise for $100 \mathrm{~min} /$ week or longer after discharge from hospital) and the group of patients who did not perform such exercise. Hazard ratio (HR), 95\% confidence intervals (CI), and P-values were calculated with the use of models adjusted for age, gender Adjusted result were adjusted for age, gender, previous percutaneous coronary intervention (PCI), restenosis lesion, use of DES, treatment for left anterior descending coronary artery (LAD), use of angiotensin converting enzyme inhibitors (ACEI) or angiotensin receptor blockers
(ARB). A probability value of $<0.05$ was considered to be statistically significant.

\section{Results}

\section{Study Population}

Between October 2004 and Descember 2007, a total of 3,705 patients assessed eligibility in this study, of whom $33(0.9 \%)$ were subsequently excluded because of access site hematoma, pain, and withdrawal of consent. Therefore, 3,672 patients were enrolled, with 1,592 assigned to the ET group and 2,080 to the control group (Figure 1).

\section{Baseline Demographics}

Baseline demographics are shown in Table 1. The ET group included many young male patients with a history of PCI and new lesions that were present in the right coronary artery, and not in circumflex branches. DES placement, lesions other than $\mathrm{LAD}$, and use of ACEI/ARB all tended to be higher in the ET 
A

Intention-to-treat analysis

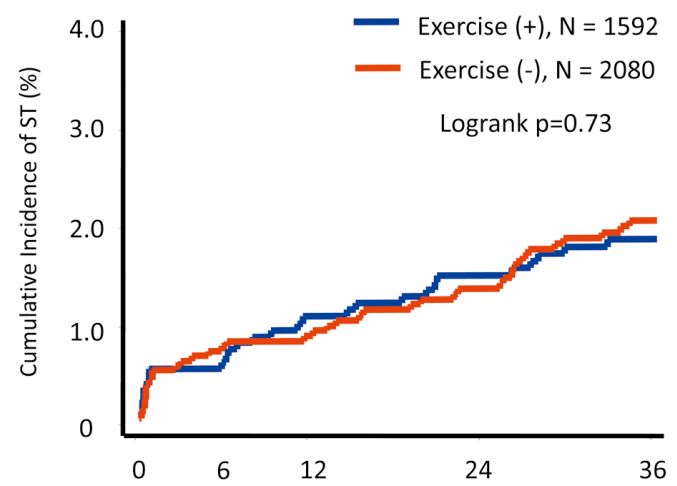

Time after Stenting (Months)

$\begin{array}{llllll}\text { Exercise (+) } & 1592 & 1522 & 1457 & 1374 & 1276 \\ \text { Exercise (-) } & 2080 & 1960 & 1900 & 1783 & 1569\end{array}$

B As-treated analysis

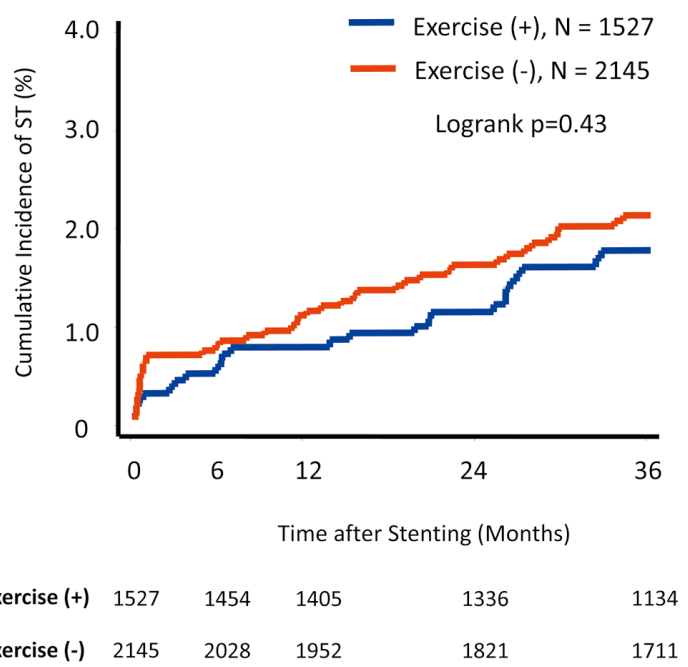

Figure 2. Cumulative incidence of stent thrombosis (ST). (A) Intention-to-treat analysis, (B) as-treated analysis. The incidence of ST was similar in both groups (A: $1.82 \%$ vs. $2.01 \%, P=0.73$, B: $1.72 \%$ vs. $2.08 \%, P=0.43$, respectively).

A

Intention-to-treat analysis

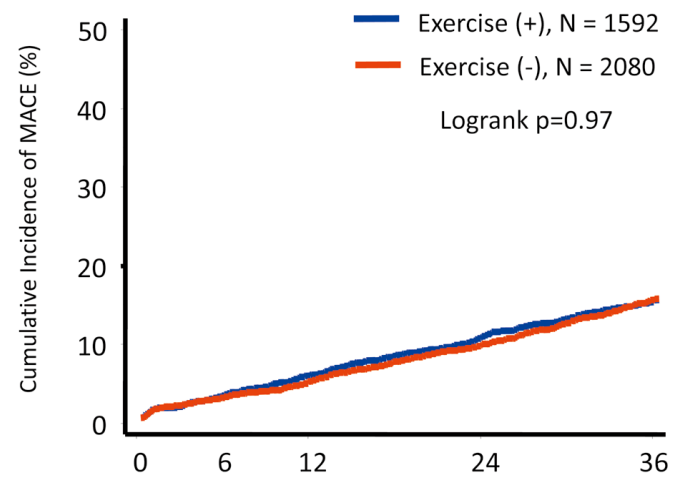

Time after Stenting (Months)

$\begin{array}{lrrrrr}\text { Exercise (+) } & 1592 & 1509 & 1433 & 1323 & 1200 \\ \text { Exercise (-) } & 2080 & 1953 & 1875 & 1723 & 1470\end{array}$

B As-treated analysis

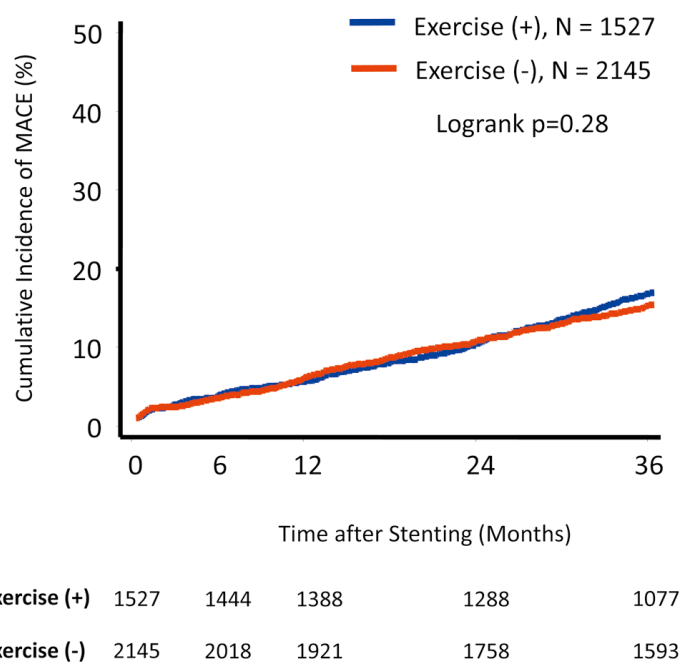

Figure 3. Cumulative incidence of major adverse cardiovascular events (MACE; includes death, myocardial infarction, and stroke). (A) Intention-to-treat analysis, (B) as-treated analysis. The incidence of MACE was similar in both groups (A: $14.9 \%$ vs. $15.0 \%$, $\mathrm{P}=0.97$, B: $15.9 \%$ vs. $14.3 \%, \mathrm{P}=0.28$, respectively).

group. There were no differences in stent length, number of implanted stents, chronic complete obstruction, and lesions at bifurcation areas between the 2 groups. No other baseline characteristics differed significantly between the groups (Table 1 ). The ET group included significantly fewer elderly patients $(>70$ years old) $(49.8 \%$ vs. $55.6 \%, \mathrm{P}<0.0001)$ and female patients (22.0\% vs. $28.4 \%, \mathrm{P}<0.0001)$.

\section{Compliance}

Patients with an exercise habit before the procedure accounted for $26.8 \%$ of the exercise group and $28.5 \%$ of the control group, with no significant difference between the 2 groups $(\mathrm{P}=0.24)$. Of 1,592 patients in the exercise group, $714(44.8 \%)$ did not continue ET during the observation period, whereas 649 (31.2\%) in the control group developed an exercise habit during this period. 


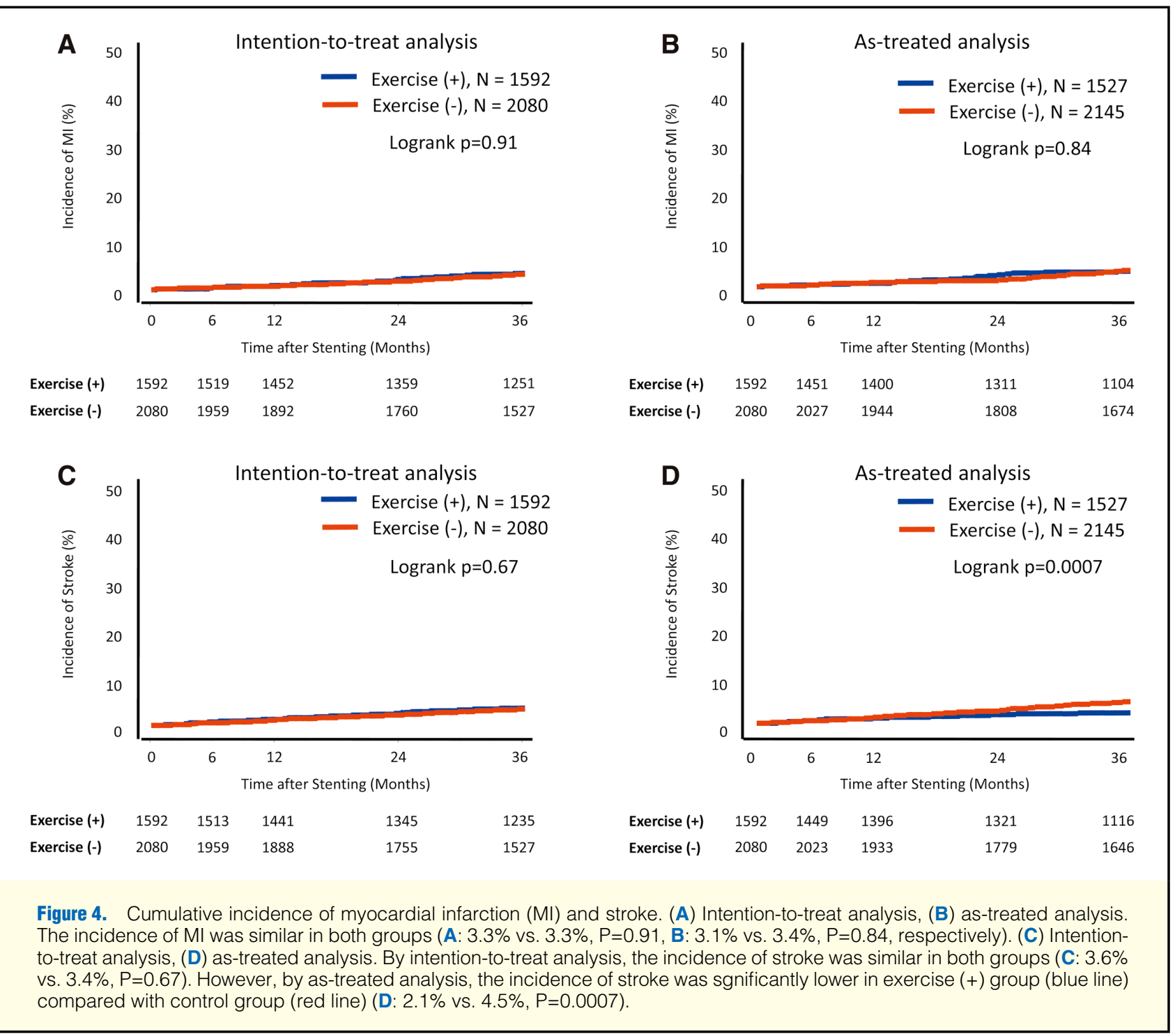

Therefore, 1,527 patients (41.6\%) had an exercise habit after the procedure. The persistence rate of ET in patients who had an exercise habit before procedure was higher than that in patients who had no such habit $(78.5 \%$ vs. $27.4 \%, \mathrm{P}<0.0001)$. The ET persistence rate was significantly lower in elderly patients $(>70$ years old) $(50.8 \%$ vs. $54.8 \%, \mathrm{P}=0.016)$, and this rate tended to be low in female patients $(24.0 \%$ vs. $26.8 \%, \mathrm{P}=0.06)$.

\section{Primary and Secondary Endpoints}

During the observation period, death occurred in 309 patients, and 423 patients dropped out or withdrew informed consent. Clinical follow-up was completed in $87.4 \%$ (2,940/3,363). ST was found in 65 patients $(1.8 \%)$, including 28 with definite ST, 11 with probable ST, and 26 with possible ST. None of the 28 patients with definite ST in the current study developed ST during or after exercise, and there was no difference in the incidence of ST between the ET and control groups $(0.69 \%$ vs. $0.82 \%, \mathrm{P}=0.66$ ). There was no significant difference in the incidence of ST between the ET and control groups in ITT analysis $(1.82 \%$ vs. $2.01 \%, \mathrm{P}=0.73)$ or $\mathrm{AT}$ analysis $(1.72 \%$ vs. $2.08 \%, \mathrm{P}=0.43$ ) (Figure 2 ). Regarding the elderly ( $>70$ years old) and gender, the incidences of ST were also similar between the younger and older groups $(1.69 \%$ vs. $1.85 \%, \mathrm{P}=0.70)$ or between male and female gender $(1.49 \%$ vs. $1.87 \%, \mathrm{P}=0.45)$.

There was also no significant difference in MACE between the 2 groups in ITT analysis $(14.9 \%$ vs. $15.0 \%, \mathrm{P}=0.97)$ or AT analysis ( $15.9 \%$ vs. $14.3 \%, \mathrm{P}=0.28$ ) (Figure 3 ). The incidences of MACE were equivalent to those in elderly or male patients (elderly vs. younger; $13.4 \%$ vs. $14.5 \%, \mathrm{P}=0.34$, female vs. male; $13.5 \%$ vs. $14.1 \%, \mathrm{P}=0.70$ ). Regarding the details of MACE, the incidence of MI did not differ significantly in ITT analysis (3.3\% vs. $3.3 \%, \mathrm{P}=0.91)$ or AT analysis $(3.1 \%$ vs. $3.4 \%$, $\mathrm{P}=0.84)$; but the incidence of stroke was signficantly lower in the ET group in AT analysis (2.1\% vs. $4.5 \%, \mathrm{P}=0.0007)$, but was similar in ITT analysis (3.6\% vs. $3.4 \%, \mathrm{P}=0.67$ ) (Figure 4). All-cause mortality was higher in the ET group in AT analysis (11.2\% vs. $7.4 \%, \mathrm{P}=0.0005)$, but did not differ significantly between the 2 groups in ITT analysis $(9.1 \%$ vs. $8.9 \%, \mathrm{P}=0.82)$. Non-cardiac death was significantly higher in the ET group (7.9\% vs. $4.3 \%, \mathrm{P}<0.0001)$, whereas cardiac death was similar in the 2 groups $(2.5 \%$ vs. $2.7 \%, \mathrm{P}=0.75)$.

Regarding DES, the incidence of ST at 3 years was $2.5 \%$ (definite ST 1.3\%). The incidence of ST in patients with a DES was significantly higher than that in patients with a BMS 

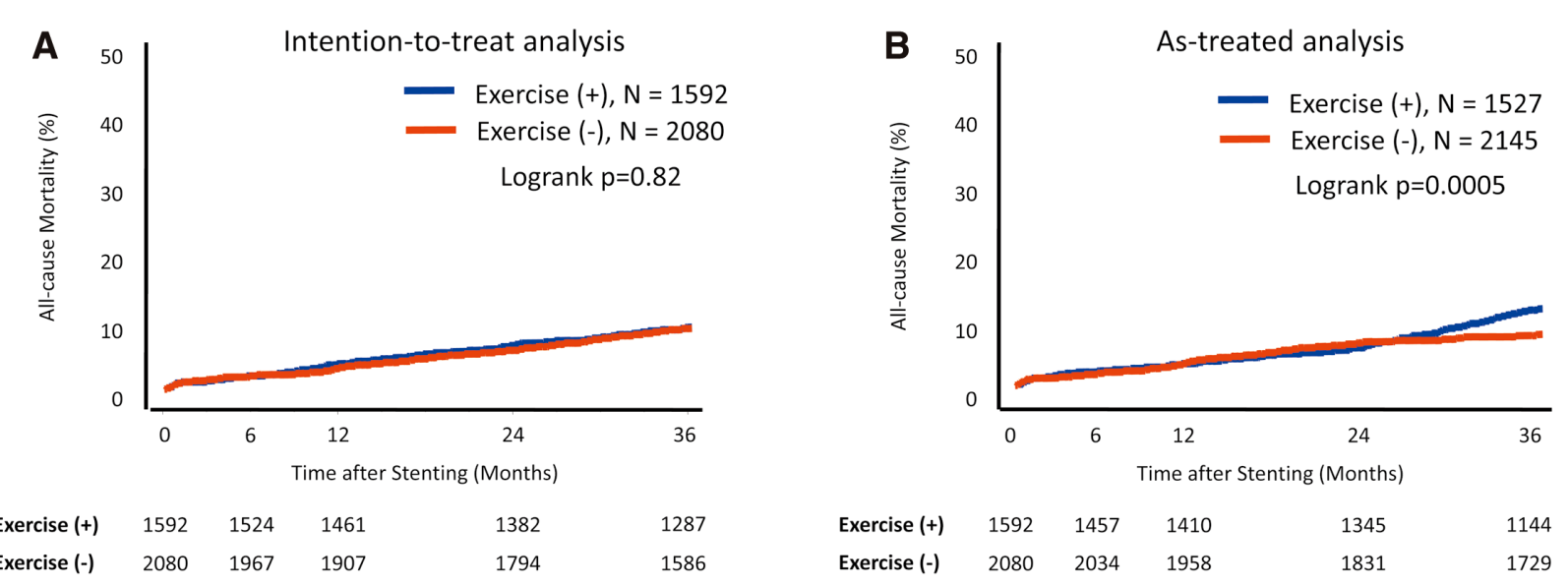

$\begin{array}{llllll}\text { Exercise (+) } & 1592 & 1524 & 1461 & 1382 & 1287 \\ \text { Exercise (-) } & 2080 & 1967 & 1907 & 1794 & 1586\end{array}$

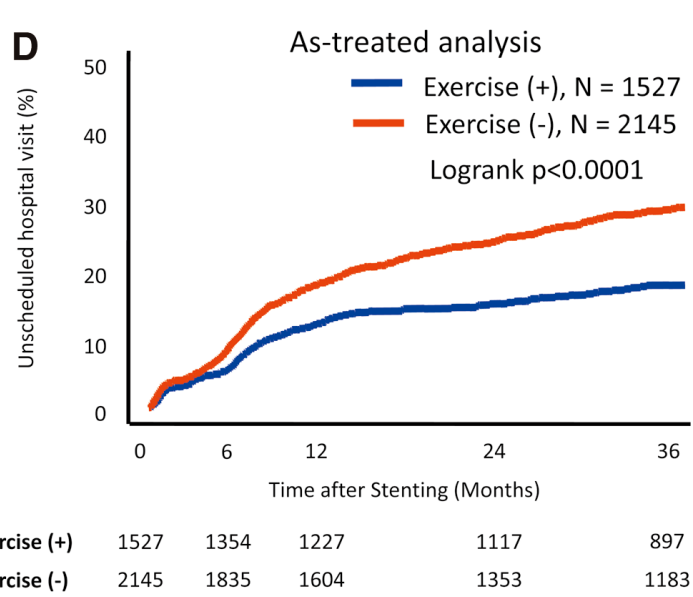

$\begin{array}{llllll}\text { Exercise (+) } & 1592 & 1412 & 1286 & 1149 & 1043 \\ \text { Exercise (-) } & 2080 & 1777 & 1545 & 1321 & 1038\end{array}$

Figure 5. Cumulative incidence of all-cause mortality and unscheduled hospital visit for worsening angina. (A) Intention-to-treat analysis, (B) as-treated analysis. By intention-to-treat analysis, the incidence of all-cause mortality was similar in both groups (C: $9.1 \%$ vs. $8.9 \%, P=0.82)$. However, by as-treated analysis, the incidence of mortality was sgnificantly higher in exercise $(+)$ group (blue line) compared with control group (red line) (D: $11.2 \%$ vs. 7.4\%, P=0.0005). (C) Intention-to-treat analysis, (D) as-treated analysis. In each analysis, unscheduled hospital visit for worsening angina was sgnificantly lower in the exercise (+) group (blue line) compared with control group (red line) (C: $20.2 \%$ vs. $27.2 \%, P<0.0001$, D: $17.6 \%$ vs. $28.8 \%, P<0.0001$, respectively.

\begin{tabular}{|c|c|c|c|c|c|c|}
\hline Outcome & $\begin{array}{c}\text { Exercise }(+) \\
(n=1,592)(\%)\end{array}$ & $\begin{array}{l}\text { Exercise }(-) \\
(n=2,080)(\%)\end{array}$ & $\begin{array}{l}\text { Unadjusted HR } \\
(95 \% \mathrm{Cl})\end{array}$ & $P$ value & $\begin{array}{l}\text { Adjusted HR } \\
(95 \% \mathrm{Cl})\end{array}$ & $P$ value \\
\hline \multicolumn{7}{|l|}{ Primary endpoint } \\
\hline Incidence of ST & $27(1.7 \%)$ & $38(1.8 \%)$ & $0.92(0.56-1.50)$ & 0.73 & $0.86(0.53-1.42)$ & 0.56 \\
\hline \multicolumn{7}{|l|}{ Secondary endpoints } \\
\hline MACE (death, MI, or stroke) & $224(14.1 \%)$ & $288(13.8 \%)$ & $1.00(0.84-1.20)$ & 0.97 & $0.98(0.82-1.17)$ & 0.83 \\
\hline $\mathrm{Ml}$ & $47(3.0 \%)$ & $59(2.8 \%)$ & $1.02(0.70-1.50)$ & 0.91 & $1.00(0.68-1.48)$ & 0.99 \\
\hline Stroke & $52(3.3 \%)$ & $62(3.0 \%)$ & $1.09(0.75-1.57)$ & 0.67 & $1.10(0.75-1.59)$ & 0.64 \\
\hline All-cause death & $137(8.6 \%)$ & $172(8.3 \%)$ & $1.03(0.82-1.28)$ & 0.82 & $0.99(0.79-1.24)$ & 0.90 \\
\hline $\begin{array}{l}\text { Unscheduled hospital visit } \\
\text { for worsening angina }\end{array}$ & $298(18.7 \%)$ & $514(24.7 \%)$ & $0.71(0.61-0.81)$ & $<0.0001$ & $0.67(0.58-0.77)$ & $<0.0001$ \\
\hline
\end{tabular}

Adjusted result were adjusted for age, gender, previous $\mathrm{PCl}$, restenosis lesion, use of drug-eluting stent, treatment for left anterior descending coronary artery, use of ACEI or ARB.

$\mathrm{HR}$, hazard ratio; $\mathrm{Cl}$, confidence interval; MACE, major adverse cardiovascular events; $\mathrm{Ml}$, myocardial infarction. Other abbreviations see in Table 1. 
( $2.5 \%$ vs. $1.2 \%, \mathrm{P}=0.002)$. However, the patients with a DES were older $(68.6 \pm 9.0$ vs. $67.9 \pm 9.3, \mathrm{P}=0.02)$ and had more frequent $\mathrm{LAD}(51.6 \%$ vs. $46.5 \%, \mathrm{P}=0.002)$, left main trunk disease $(2.9 \%$ vs. $1.6 \%, \mathrm{P}=0.005)$, in-stent restenosis $(19.7 \%$ vs. $16.2 \%, \mathrm{P}=0.006)$, total number of stent $(1.7 \pm 0.9$ vs. $1.5 \pm 0.8 \mathrm{~mm}$, $\mathrm{P}<0.0001)$, a longer total stent length $(31.7 \pm 18.0$ vs. $29.3 \pm$ $15.4 \mathrm{~mm}, \mathrm{P}<0.0001)$, $\mathrm{LV}$ dysfunction $(10.5 \%$ vs. $7.2 \%, \mathrm{P}=0.0003)$, and previous PCI (18.0\% vs. $14.8 \%, \mathrm{P}=0.008)$ compared with those with a BMS.

The rate of unscheduled hospital visits for worsening angina was significantly lower in the ET group in ITT analysis $(20.2 \%$ vs. $27.2 \%, \mathrm{P}<0.0001)$ and $\mathrm{AT}$ analysis $(17.6 \%$ vs. $28.8 \%$, $\mathrm{P}<0.0001$ ) (Figure 5).

After correction of each endpoint for age, gender, previous PCI, restenosis lesion, use of DES, treatment for LAD, and use of ACEI/ARB, the ET group had no significant increase in incidence of ST (HR 0.86, 95\% CI 0.53-1.42, adjusted $\mathrm{P}=0.56$ ), MACE (HR 0.98, 95\%CI 0.82-1.17, adjusted $\mathrm{P}=0.83$ ), MI (HR 1.00 , 95\% CI 0.68-1.48, adjusted $\mathrm{P}=0.99$ ), stroke (HR 1.10, 95\%CI 0.75-1.59, adjusted $\mathrm{P}=0.64)$, or all-cause mortality (HR $0.99,95 \%$ CI $0.79-1.24$, adjusted $\mathrm{P}=0.90$ ). Exercise was effective for prevention of unscheduled hospital visits for worsening angina (HR 0.67, 95\% CI 0.58-0.77, adjusted $\mathrm{P}<0.0001$ ) (Table 2).

\section{Discussion}

Mortality during exercise has been found to be low in patients with cardiac disease. ${ }^{13}$ Consistent with this finding, there was no ST during or after exercise in this study. All-cause mortality in the ET group was higher in AT analysis, although the rates in the 2 groups were similar in ITT analysis. However, the rate of non-cardiac death was significantly higher in the ET group, whereas the rate of cardiac death was not statistically significant in the 2 groups. Randomized controlled trials of ET in ischemic cardiac disease have shown lower ${ }^{5,6}$ or equivalent ${ }^{1,2}$ mortality, but none have shown increased mortality with ET. In our study, non-cardiac death occurred in the second year or later in many cases, often due to malignancy. Thus, it is unlikely that exercise was directly involved in these deaths.

With respect to patients who received DES implantation, DES was used in $45.7 \%$ of the study population. Although the incidence of ST in patients with a DES was significantly higher than that in patients with a BMS, the DES was preferred over the BMS for patients with a complex lesion and severe background contributed to the result. In addition, delayed endothelialization with DES might explain the higher ST incidence. There is no significant difference in body mass index between the 2 groups.

Unscheduled rehospitalization for worsening angina was observed in 530 patients. Of them, coronary angiogram or coronary computed tomography was performed in all patients. The causes of angina were ST (5 patients), restenosis at the stented site (248 patients), new lesion (177 patients), no change (67 patients), and spasm (33 patients). Approximately, half of the culprit lesions were a restenosis lesion in the entire cohort.

Many elderly patients have multiple diseases and it is difficult to use ET in these cases. In addition, the safety of ET for elderly patients with coronary disease remains unclear. The rate of participation in ET is low in elderly patients ${ }^{14}$ and is especially low in female elderly patients. ${ }^{15}$ In the current study, the ET group included significantly fewer elderly patients (aged $\geq 70$ years old) and female patients. The continuation rate of ET during follow-up period was lower in elderly and female patients. However, the incidences of ST and MACE in elderly patients were equivalent to those in younger patients. In female patients, the incidences of ST and MACE were similar between the younger and older groups, which suggests that ET is safe for elderly and female patients. Previous report also suggested that. ${ }^{16}$

Improvement of exercise tolerability after ET has been shown not to differ between elderly and young patients, ${ }^{17,18}$ and a similar improvement in male and female patients has also been reported. ${ }^{15}$ These data and the results of the current study indicate that active participation in ET should be recommended for elderly and female patients.

In the present study, we also found that continuity of exercise was difficult for patients in the ET group. Although the patients voluntarily selected ET upon discharge from hospital, the rate of persistence of exercise was $55.2 \%$. In the HF-ACTION trial, ${ }^{19,20}$ the efficacy of ET in patients with cardiac failure was evaluated, and only about $30 \%$ of the patients maintained ET at $120 \mathrm{~min} /$ week over the study period. In addition, in our study, $55 \%$ of the patients in the group treated only with drug therapy complained about not receiving ET, and many of these patients voluntarily performed exercise. Therefore, this might have reduced the difference in endpoints as a result of crossover effects. Of the patients in the control group, $31.2 \%$ voluntarily began and continued exercise, and $76.9 \%$ (499 of 649) of these patients had a past exercise habit. The continuation rate of ET in patients with exercise habit was higher than that in patients without such habit, and thus greater effects of ET are likely in patients with an exercise habit. Patients who have an exercise habit do not need to suspend exercise after PCI and should participate in ET. This is particularly important because ET has been shown to improve both angina, ${ }^{4}$ and anxiety and depression, ${ }^{7,8}$ which might contribute to decreasing unscheduled hospital visits for worsening angina. In the ETICA trial, ${ }^{21}$ the rate of re-hospitalization in the ET group was low, despite the patients having a similar incidence of restenosis after PCI compared to controls, and this finding is supported by the results of the current study.

\section{Study Limitations}

This study has several limitations. First, although it was performed as a large-scale prospective study, it was also a single center, non-randomized study. Therefore, a multicenter randomized trial is needed to verify the findings. Second, most of the DES used in this study $(84.8 \%)$ were sirolimus-eluting stents, a first-generation DES. Thus, further studies should be performed using more recent stents. In addition, lifelong dual antiplatelet therapy was performed for patients with DES placement. No increase in ST has been reported when drug therapy was changed to single administration of aspirin at 6 months or later, ${ }^{22}$ but it is unclear whether similar effects would be obtained after decreasing the dose of antiplatelet drug. Third, because patients volunteered for participation in ET, there was a self-selection bias in the study. In addition, because ET was performed based on subjective exercise intensity under no supervision, self-reported data were used to determine whether appropriate exercise with a sufficient burden was actually performed. This suggests that a study using ET based on objective markers under supervision is required to validate our findings, although the ET based on the Borg scale is useful as a tool of self-monitoring exercise. ${ }^{23}$ Finally, crossover was observed in many patients in both groups regarding exercise, and this might have affected the endpoints. To compensate for this limitation, we performed an AT analysis. 


\section{Conclusion}

Moderate ET based on the Borg scale after successful coronary stenting does not increase the incidence of ST and MACE up to 3 years, and was effective for reducing unscheduled hospital visits for worsening angina.

\section{Acknowledgments}

The authors are indebted to Ryoko Kanzaki, Tazuko Kimura, Yoshihiro Noda, Seiji Shimada, Tomoyuki Ishimaru, and Shyoko Soga for assistance in collecting clinical data.

\section{Disclosures}

Financial Support: None. Conflict of Interest: None of the authors have a real or perceived conflict of interest regarding the work in the manuscript.

\section{References}

1. DeBusk RF, Miller NH, Parker KM, Bandura A, Kraemer HC, Cher DJ, et al. Care management for low-risk patients with heart failure: A randomized, controlled trial. Ann Intern Med 2004; 141: 606-613.

2. Haskell WL, Alderman EL, Fair JM, Maron DJ, Mackey SF, Superko $\mathrm{HR}$, et al. Effects of intensive multiple risk factor reduction on coronary atherosclerosis and clinical cardiac events in men and women with coronary artery disease: The Stanford Coronary Risk Intervention Project (SCRIP). Circulation 1994; 89: 975-990.

3. Hertzeanu HL, Shemesh J, Aron LA, Aron AL, Peleg E, Rosenthal $\mathrm{T}$, et al. Ventricular arrhythmias in rehabilitated and nonrehabilitated post-myocardial infarction patients with left ventricular dysfunction. Am J Cardiol 1993; 71: 24-27.

4. Froelicher V, Jensen D, Genter F, Sullivan M, McKirnan MD, Witztum $\mathrm{K}$, et al. A randomized trial of exercise training in patients with coronary heart disease. JAMA 1984; 252: 1291-1297.

5. Newton M, Mutrie N, McArthur JD. The effects of exercise in a coronary rehabilitation programme. Scott Med J 1991; 36: 38-41.

6. Taylor CB, Houston-Miller N, Ahn DK, Haskell W, DeBusk RF. The effects of exercise training programs on psychosocial improvement in uncomplicated postmyocardial infarction patients. J Psychosom Res 1986; 30: 581-587.

7. P.RE.COR. Group. Comparison of a rehabilitation programme, a counselling programme and usual care after an acute myocardial infarction: Results of a long-term randomized trial. Eur Heart J 1991; 12: 612 616.

8. Lamm G, Denolin H, Dorossiev D, Pisa Z. Rehabilitation and secondary prevention of patients after acute myocardial infarction: WHO collaborative study. Adv Cardiol 1982; 31: 107-111.
9. Mark DB, Naylor CD, Hlatky MA, Califf RM, Topol EJ, Granger CB, et al. Use of medical resources and quality of life after acute myocardial infarction in Canada and the United States. N Engl J Med 1994; 331: $1130-1135$.

10. TIMI Study Group. The Thrombolysis in Myocardial Infarction (TIMI) trial: Phase I findings. N Engl J Med 1985; 312: 932-936.

11. Borg GA. Phychophysical bases of perceived exertion. Med Sci Sports Exerc 1982; 14: 377-381.

12. Cutlip DE, Windecker S, Mehran R, Boam A, Cohen DJ, van Es GA, et al. Clinical end points in coronary stent trials: A case for standardized definitions. Circulation 2007; 115: 2344-2351.

13. Van Camp SP, Peterson RA. Cardiovascular complications of outpatient cardiac rehabilitation programs. JAMA 1986; 256: 1160-1163.

14. Lavie CJ, Milani RV, Littman AB. Benefits of cardiac rehabilitation and exercise training in secondary coronary prevention in the elderly. J Am Coll Cardiol 1993; 22: 678-683.

15. Ades PA, Waldmann ML, Polk DM, Coflesky JT. Referral patterns and exercise response in the rehabilitation of female coronary patients aged greater than or equal to 62 years. Am J Cardiol 1992; 69: 1422 1425.

16. Onishi T, Shimada K, Sato H, Seki E, Watanabe Y, Sunayama S, et al. Effects of phase III cardiac rehabilitation on mortality and cardiovascular events in elderly patients with stable coronary artery disease. Circ J 2010; 74: 709-714.

17. Ades PA, Waldmann ML, Gillespie C. A controlled trial of exercise training in older coronary patients. J Gerontol A Biol Sci Med Sci 1995; 50A: M7-M11.

18. Ades PA, Waldmann ML, Poehlman ET, Gray P, Horton ED, Horton ES, et al. Exercise conditioning in older coronary patients: Submaximal lactate response and endurance capacity. Circulation 1993; 88: $572-577$.

19. O'Connor CM, Whellan DJ, Lee KL, Keteyian SJ, Cooper LS, Ellis SJ, et al. Efficacy and safety of exercise training in patients with chronic heart failure: HF-ACTION randomized controlled trial. JAMA 2009; 301: 1439-1450.

20. Flynn KE, Piña IL, Whellan DJ, Lin L, Blumenthal JA, Ellis SJ, et al. Effects of exercise training on health status in patients with chronic heart failure: HF-ACTION randomized controlled trial. JAMA 2009; 301: $1451-1459$.

21. Belardinelli R, Paolini I, Cianci G, Piva R, Georgiou D, Purcaro A. Exercise training intervention after coronary angioplasty: The ETICA trial. J Am Coll Cardiol 2001; 37: 1891-1900.

22. Kimura T, Morimoto T, Nakagawa Y, Tamura T, Kadota K, Yasumoto $\mathrm{H}$, et al. Antiplatelet therapy and stent thrombosis after sirolimuseluting stent implantation. Circulation 2009; 119: 987-995.

23. Carvalho VO, Bocchi EA, Guimarães GV. The Borg scale as an important tool of self-monitoring and self-regulation of exercise prescription in heart failure patients during hydrotherapy: A randomized blinded controlled trial. Circ J 2009; 73: 1871-1876. 